\title{
Basic research comes alive in Japan
}

The richest country in the world seems to have acquired a broadened basis for basic research that promises both serious competition with the West and a distinctive style.

\section{Tokyo}

NOBODY seems to have a clear view of the bearing of last week's dramatic upheaval in the politics of Japan on the future of basic science, even if the continued prosperity of Japanese technology seems assured. Part of the uncertainty arises because the opposition parties that secured two-thirds of the vacant seats in the Upper House of the Japanese parliament differ among themselves on questions such as the future role of nuclear power or on the protection of the environment, and in any case have said very little about the function of basic science in the Japanese scheme of things.

If there is a common theme in what the opposition parties say other than their view that corrupt governments are undesirable, it is that they abhor the new 3 per cent consumption tax. But the chances are that the ruling Liberal Democratic Party, frightened by the election result, will move quickly to modify the tax, making it less unpalatable. In principle, that could affect the government's willingness to spend public funds on the improvement of research support, especially in the universities. But the general opinion is that the bureaucrats who run the ministries have acquired such a taste for improvement, and are in any case so powerful, that the cheerful tendencies of the past few years can only continue.

For decades, it has been a glaring paradox that Japan, while heading for unparalleled and inimitable prosperity, should have so neglected its universities and their capacity for research. Now that Japan is literally the richest country (with a gross domestic product of $\$ 23,000$ per head of population in 1988), the signs of neglect are still apparent in the older buildings. But the idea that things are on the mend is almost palpable.

All this is most obvious in people's demeanour. One noticeable change is that the once-familiar excess of politeness has melted away, to be replaced by a more general courtesy. Even the practice of thrusting a visiting-card (called a namecard) at every visitor is no longer universal (and some apologize for not having one). The result is that it is easier to hold straightforward conversations even about questions which are largely Japanese (such as the future of the government). To say that people are more confident of themselves in relation to their competitors in the West would be demeaning, and probably incor- rect as well. Rather it is that there appears to be many more active people with a detailed knowledge of and curiosity about what similar groups elsewhere are doing.

There have also been institutional changes. In some fields, high-energy physics, for example, the recent successes of national research programmes seem to have had an almost tangible effect on people's morale. The electron accelerator at the Tskuba laboratory called KEK is a proof not merely that Japanese can build big machines, which was hardly ever in doubt, but that they can use them for sound physics as well. In the same way, people are delighted that the Japanese neutrino detector seems to have functioned as well as that of the predominantly Irvine-Brookhaven collaboration in detecting a bunch of neutrinos from the supernova 1987A.

That, no doubt, is why some at least of the physics community are resentful of the rumours widely circulating that, as part of the negotiations between the United States and Japan on their disputed trading relationship, Japan is being asked both to contribute to the cost of the Superconducting Super-Collider to be built in Texas and to commit the Japanese community to detectors for that machine. At least some people say they would prefer Japan to invest in the European machine (LEP) at Geneva.

US negotiators may not appreciate how much resentment they have engendered over issues such as these; to point out that the Government of Japan spends a smaller proportion of its income on basic research than does the government of the United States may be correct, but to imply that natural justice requires more spending in Japan, and to go on to specifiy how a substantial number of Japanese should occupy themselves, seems tactless, to say the least.

Other institutional changes could have an even more profound influence on the future. Among other things, a group of national laboratories led by the three national research institutes at Okazaki have successfully created their National Graduate University - a degree-giving institution now boasting of nearly $50 \mathrm{PhD}$ students. In the years ahead, there is bound to be intensifying rivalry between this institution without a central campus, dependent as it is on recruitment of students from the 96 national universities and the national universities themselves.
Among academics proper, there is much unfamiliar talk of mobility and diversity. At least at the universities of Tokyo and Kyoto, it seems to be agreed that it will be neither feasible nor desirable simultaneously to improve the status of research at each of the national universities. That is why people at these institutions are full of praise for schemes being devised by bureaucrats at the education ministry (almost affectionately known as Mombishu) for imparting a sense of competition to the annual pursuit of financial support.

It is true that one such device, Mombishu's scheme for awarding large research grants worth up to the equivalent of $\$ 1$ million a year too often go to predictable safe hands and, sometimes, are spent on over-ambitious projects. (But Japan would not be what it is without a measure of calculated recklessness.) Similarly, the national graduate university is welcomed (but not at Tokyo, which has ambitions to assume the role itself) as a means by which able young people from all parts of the national university system will be put into general academic circulation.

Meanwhile, some universities have found ways round the straitjacket of uniformity Mombishu traditionally imposes on itself. Kyoto has, for example, used private funds to create two new institutes on its campus - one to span the interface between computer science and psychology - and, with Osaki, is well launched on a scheme to found an Institute of Advanced Study 500 kilometres away from Tokyo.

However the funds arise, there seems no doubt that the pattern of academic research in Japan will be distinctive. On successive mornings last week, I visited the Seiko company's development laboratory, complete with its automatic watchproduction line being used to train the managers of a new plant in Singapore, and the national laboratory called RIKEN, founded in 1917 as a means of improving Japanese science and technology. The styles are virtually identical. Young men (as yet, there are few women) are in charge of their own projects and proudly explain them, however halting their English. The two laboratories seem identical in their readiness to tackle difficult tasks. But it is no longer just a matter of making machines function: people seem to know clearly what they want them to accomplish.

John Maddox 